\title{
A POESIA É O MUNDO SENDO: O POEMA NA SALA DE AULA
}

\section{POETRY IS THE WORLDS BEING: THE POEM IN THE CLASSROOM}

\section{Christina Bielinski Ramalho* \\ Universidade Federal de Sergipe}

RESUMO: Reflexões sobre a presença do poema nas salas de aula de instituições de ensino básico e superior, com foco especial em pesquisa recentemente concluída intitulada "No meio do caminho tinha um poema: repensando as teorias e as práticas em torno dessa presença”. Dimensionamento das bases teóricas, incluindo documentos oficiais como os PCNs, que incidiram para a elaboração de testes de sondagem nos três níveis, com destaque para Lipovetsky, Serroy, Gens e Cereja.

PALAVRAS-CHAVE: Poesia brasileira. Ensino. Leitura.

ABSTRACT: Reflections on the presence of the poem in the classrooms of basic and higher education institutions, with special focus on a research recently completed entitled "Halfway had a poem: rethinking theories and practices around that presence." Scaling of theoretical bases, including official documents such as $P C N s$, related to the preparation of probing tests on the three levels, with emphasis on Lipovetsky, Serroy, Gens and Cereja.

KEYWORDS: Brazilian poetry. Teaching. Reading.

\footnotetext{
Doutora em Letras pela UFRJ (Ciência da Literatura, 2004), desenvolveu pesquisa de Pós-doutorado na USP/FAPESP (2010-2012) sobre a épica cabo-verdiana. Professora de Literaturas de Língua Portuguesa e Estágio Supervisionado da Universidade Federal de Sergipe (UFS). Campus Itabaiana, Sergipe, Brasil. E-mail: ramalhochris@ufs.br
} 


\section{A POESIA É O MUNDO SENDO: O POEMA NA SALA DE AULA}

\section{INTRODUÇÃO}

Neste texto apresentam-se algumas reflexões sobre a presença do poema nas salas de aula de instituições de ensino fundamental e médio e de cursos de licenciatura em Letras, temática que serviu de base a dois projetos de pesquisa: "No meio do caminho tinha um poema: repensando as teorias e as práticas em torno dessa presença", desenvolvido no curso Letras da Universidade Federal de Sergipe, campus Itabaiana, de março de 2012 a julho de 2013; e "A poesia no ensino médio: repensando as teorias e as práticas em torno dessa presença", iniciada na mesma instituição em agosto de 2013 e em fase de análise de dados obtidos por meio de testes de sondagem aplicados em turmas de ensino médio de diversas instituições de ensino do estado de Sergipe. A amplitude da investigação se completa com a pesquisa de Mestrado Profissionalizante em Letras (PROFLETRAS) sobre a presença do poema no ensino fundamental, atualmente em desenvolvimento por Rosivânia de Souza Menezes.

Da teoria à observação dos resultados práticos, o objetivo desta abordagem é unir as pontas da reflexão e da ação em nome de uma filosofia direcionada à superação dos entraves por que passa a formação de leitores no Brasil, em especial no que se refere ao letramento lírico. 
Para dar início a essas reflexões, ressaltando a visão básica de que o poema como corpus exige a aceitação de seu caráter plurissignificativo, retomo um texto que escrevi, a pedido de um ex-aluno do curso de Letras da Universidade Veiga de Almeida, onde lecionei, e atualmente professor de Literatura dedicado ao ensino médio. Certa ocasião, esse professor reuniu diversos depoimentos de poetas, para, posteriormente, utilizá-los em sala de aula para discutir, com seus alunos, o tema "criação lírica". Recordando-se de meu envolvimento com a poesia, ele me pediu um texto por meio do qual eu explicasse o porquê de se escreverem poemas. "Território lírico" foi a resposta à sua solicitação:

Um corpo poroso. Um mata-borrão. Um sentimento de urgência atado ao dia-a-dia. Movimento de resistência às forças que estagnam. Mola-mestra para as tentativas de tradução dos enigmas do mundo. Desejo vivo de ir além da morte. Filtro colocado na boca do esgoto. Rosa dos ventos. Biruta, indicando os ventos; biruta, amalucando o planeta. Galo cantando manhãs. Cigarra cantando tardes. Coruja piando noites. Panfleto vermelho jogado no chão. Munição, arma, desejo de guerra. Mansidão, flor, desejo de paz. Teia de aranha nas prateleiras. Folha no chão dizendo "É outono!". Suor no rosto dizendo "É verão!". Cachecol no pescoço dizendo “É inverno!". E todas as primaveras no corpo ao mesmo tempo. Ampulheta acionada pela voz da urgência. Onda batendo forte, onda serpenteando mansa. Farol no meio do mar. Oásis no deserto. Pronto Socorro. 0800. Palavras gritando contra o silêncio que aflige. Palavra revestida de outra palavra. Palavra reinventada na boca de espera. Palavra ensimesmada querendo amigo. Palavra em estado de graça plantada na realidade sem graça. Palavra ainda sem nome nascendo dos acontecimentos. Palavra surda e muda com linguagem de sinais própria. Palavra com medo. 
Palavra sem medo. Palavra sem dinheiro. Palavra que não se cala. Palavra que canta. Eis o poetar.

E por que poetar? Porque, além das livrarias e das bibliotecas, além dos comércios e dos críticos, além muito além do improvável sucesso, há, no poeta/na poetisa, uma angústia incessante de dizer, no sentido transitivo - de expor, enunciar, exprimir por palavras; proferir; discursar; recitar, declamar; mandar, ordenar; rezar; mostrar, indicar; referir, narrar; dar a conhecer, apregoar; apontar, censurar; supor, imaginar; afirmar, asseverar; estar inclinado a crer, ter opinião, parecer; chamar, denominar; aconselhar, persuadir -, aquilo que lhe (ao poeta ou à poetisa) vem como verbo intransitivo. Poetar, porque, acima das antologias e das histórias literárias, acima das feiras e das bienais, acima muito acima das listas dos mais lidos, há, neste "ser que cria", um livro infinito a ser escrito em forma de livros finitos. Há, no poeta, um menino sempre vivo que fala o que sente porque é menino, e um velho, muito velho e sabido, que converte em símbolos as palavras do menino, para que este não apanhe e deixe, por isso, de ser menino. E, se o poeta é uma mulher, há, igualmente, nela, a menina viva e a velha sábia driblando os obstáculos.

E porque o poetar não exige tempo nem espaço para existir como pulsão; e porque o tempo e o espaço se inscrevem no poetar como matéria-prima de uma fábrica preexistente; o poeta (e o contista e o cronista e o romancista e o dramaturgo e todas essas palavras no feminino), escravo/a do fabricar, vive, ele/a próprio/a, além das fronteiras. Ontem, hoje ou amanhã, não importa. A poesia é o mundo sendo. A poesia é o gerúndio (bravamente sustentado pelo galo, pela cigarra e pela coruja) (RAMALHO, 2011, p. 72-74). 
Ainda que o longo texto citado tenha resultado de uma motivação específica, creio que a definição “a poesia é o mundo sendo" sintetiza, metaforicamente, o impacto de todos os poemas no meu imaginário e, de certo modo, registra o próprio impacto que, como professora, eu gostaria que o contato com poemas provocasse na sensibilidade de estudantes de qualquer nível de ensino. Com sua linguagem cifrada, ritmada e ligeira, o poema canta a vida e convida quem dele desfruta, com atenção e sensibilidade, a recriar o sentido da vida. Contudo, os pré-requisitos "atenção" e "sensibilidade" constituem dois grandes enfrentamentos quando se pensa sobre a questão: "Como o poema se faz presente nas salas de aula do ensino fundamental, do médio e dos cursos de licenciatura em Letras no Brasil?”.

Dimensionar, a partir desse questionamento, a presença do poema nas salas de aula tornou-se um objetivo. Assim, em março de 2012, teve início a primeira pesquisa, que, posteriormente, agregou a Iniciação Científica. O ponto de partida teórico sobre o corpus em questão veio de Otávio Paz, que, de forma sucinta e lírica, atendendo, como se disse antes, à natureza do texto lírico, definiu "poesia":

A poesia é conhecimento, salvação, poder, abandono. Operação capaz de transformar o mundo, a atividade poética é revolucionária por natureza; exercício espiritual, é um método de libertação interior. A poesia revela este mundo; cria outro. Pão dos eleitos; alimento maldito. Isola; une. Convite à viagem; regresso à terra natal (1982, p.15).

A amplitude do potencial reflexivo que a poesia possui, como linguagem que é, permite que sua presença nas salas de aula, sob forma de poemas, seja encarada como um recurso importante no sentido de se interferir na qualidade do letramento lírico, incrementando o acesso dos leitores de poemas a esse potencial. Contudo, ainda que a poesia convide à viagem, no plano do cotidiano acadêmico, o poema vem, em geral, sendo tratado como um problema. E essa realidade não parte de opiniões subjetivas e generalizantes, mas de dados concretos diretamente relacionados, entre outros, a tris- 
tes estatísticas, como as que colocam o Brasil como oitavo país do mundo em percentuais de analfabetismo de pessoas adultas ${ }^{1}$, ou as que se referem ao baixo desempenho do país em pesquisas como as promovidas pelo Programme for Internacionatial Student Assessement (PISA) ${ }^{2}$, que avalia estudantes de ensino fundamental e médio nas competências Leitura, Ciência e Matemática. Se o iletrismo e o analfabetismo funcional são cânceres que afetam a sociedade brasileira, o que dizer da questão específica do letramento lírico, que, pela natureza mais complexa do texto poético, exige ainda mais sofisticada competência para a leitura?

Vejamos como essa questão ganha contornos mais definidos quando relacionada aos procedimentos e aos resultados de pesquisa específicos do projeto direcionado à presença do poema nas salas de aula da universidade, ainda que a discussão teórica apresentada a seguir contemple as discussões realizadas para a elaboração dos três testes de sondagem realizados. ${ }^{3}$

\section{O POEMA NA SALA DE AULA COMO TEMA}

O consenso geral sabe que trabalhar com o poema em sala de aula, como texto a ser lido, debatido, analisado, vivido, implica um professor, por sua condição de mediador da leitura, constantemente atualizado em relação à produção lírica - o que envolve contato direto com novas publicações e novos autores, além de uma bagagem sólida em relação à poesia universal -, e com boa e diversificada fundamentação teórica, que lhe permita elaborar metodologias de trabalho com o texto lírico que respeitem sua natureza em lugar de forçá-lo a preencher formatos teóricos. Por outro lado, é importante que o professor tenha constante disposição para, neste mundo globalizado e

1 Conforme relatório divulgado pela Organização das Nações Unidas para a Educação, a Ciência e a Cultura (UNESCO) no dia 29 de janeiro de 2014.

2 Em 2009, em pesquisa sobre competência na Leitura, o Brasil ficou em 53º entre 65 países. Ver site http://www.oecd.org/pisa/. Consulta realizada em 07/02/2014.

3 Pela extensão das pesquisas, seria impossível sintetizar em um só artigo todos os procedimentos seguidos e resultados obtidos. Contudo, de forma geral, a base teórica envolvida na elaboração dos três testes (nível superior, médio e fundamental) foi a mesma, com exceção, obviamente, de referências específicas. 
informatizado, estabelecer diálogos entre o poema e outras linguagens. Sobre o papel do professor no letramento e na ampliação da competência dos estudantes como leitores, afirma William Cereja:

Independente da forma como o professor conduz e desenvolve o projeto de leitura na escola em que atua (se por meio de provas, e debates, de trabalhos criativos, etc.), é relevante o papel que ele desempenha como orientador de leitura e como formador de leitores e do gosto literário (2005, p. 23).

De outro lado, como já se comentou, privilegiando a linguagem simbólica, o poema exige leitores mais maduros, com sensibilidade aguçada para perceber imagens, efeitos sonoros, metáforas, representações simbólicas, etc. Nesse sentido, dadas as precariedades no âmbito das práticas de leitura observadas em nosso país, o poema perde seu potencial como texto sedutor, que deslumbra, comove e faz pensar, para se tornar quase um entrave na rotina escolar e mesmo na universitária. Assim, de um lado, temos as expectativas de sucesso implícitas em documento oficiais como o $\mathrm{PCN}+$, que trabalha com o conceito de fruição como prática que deve estar presente nas escolas:

Desfrute (fruição): trata-se do aproveitamento satisfatório e prazeroso de obras literárias, musicais ou artísticas, de modo geral bens culturais construídos pelas diferentes linguagens, depreendendo delas seu valor estético. Apreender a representação simbólica das experiências humanas resulta da fruição dos bens culturais. Podem propiciar aos alunos momentos voluntários para que leiam coletivamente uma obra literária, assistam a um filme, leiam poemas de sua autoria - de preferência fora do ambiente de sala de aula: no pátio, na sala de vídeo, na biblioteca, no parque (2002, p. 67).

e, de outro, estatísticas que expressam as falhas na relação entre teoria e prática. 
De forma bastante objetiva, a condição problemática do poema na sala de aula envolve dois planos: o da formação do professor como mediador de leitura e o da formação dos estudantes como leitores. A esses dois fatores se agregam outros, de ordem econômica, política e filosófica, o que amplia gravemente a dimensão do problema, pois, na maior parte das vezes, as soluções parecem inalcançáveis aos que se predispõem a dimensionar e a discutir os contextos relacionados à realidade que se observa nas salas de aulas do país. Render-se a uma visão fatalista, contudo, não resolverá a situação. Logo, há de se acreditar na força de ações conjuntas por parte de docentes e instituições de ensino, no sentido de viabilizar o planejamento de interferências concretas que possam, de um lado, desmascarar as realidades observadas país afora, tanto no âmbito público quanto no privado, nos níveis de formação básica e superior e, de outro, elaborar propostas consistentes de intervenção com vistas a contribuir para uma transformação no panorama negativo. Assim sendo, temas como a presença do poema na sala de aula devem ganhar uma dimensão pragmática, que una teorias, dados, projetos e realizações que, em conjunto, traduzam um novo horizonte para o letramento lírico e as práticas de leitura de poemas nos mais diversos níveis de ensino. Assim, concorda-se com Leonor Werneck e Márcia Duarte, quando afirmam que:

A Literatura precisa ser encarada como fenômeno artístico, considerada em sua natureza educativa por excelência, porque traz valores, crenças, idéias, pontos de vista de seus autores, que podem enriquecer a vida daqueles que a lêem. Não deve estar presa a modismos pedagógicos e sim ser considerada como uma atividade prazerosa de conhecimento do ser humano e das diversas funções da linguagem, dentre elas a função poética, pois retrata e recria as questões humanas universais, numa linguagem esteticamente trabalhada, transgressora da rotina cotidiana (SANTOS; DUARTE, 2005, p. 4). 
O trabalho com o poema na sala de aula, portanto, exige um planejamento próprio, como, aliás, o exigem outras manifestações da literatura. E não se trata aqui de um pensamento reducionista que privilegia uma concepção engessada de gênero literário, mas um entendimento prático das demandas específicas de estratégias de leitura que se relacionam ao poema como realização linguística. Sobre esse planejamento, embora não se referindo especificamente ao poema como objeto de leitura, afirma Armando Gens:

Para os tempos atuais, um planejamento deve propor articulações, diálogos, encontros, debates e convivências entre o popular e o culto, entre o midiático e o folclore, entre as obras canônicas e as ditas marginais, entre as obras do passado e as produzidas na contemporaneidade, entre a literatura e as demais modalidades da arte. Deve, também, abrir espaços para acolher as diferenças de gosto e de estética e as implicações das cenas gráficas e computacionais em espaço literário (2009, p. 73).

A amplitude desse tipo de planejamento - capaz de atender à diversidade de demandas sociais e culturais - corresponde à própria dimensão das relações humanas nestes tempos de globalização e multiculturalismo, ou, como afirmam Lipovetsky e Serroy, de "Grande Desorientação":

Chegou o tempo em que o espaço e o tempo se globalizaram de alguma maneira: a Terra transformou-se em um microuniverso que a velocidade das redes de comunicação tornou acessível em toda parte, com uma quase instantaneidade. Mas, se o desempenho da informação - velocidade e abundância ilimitada - deu um excepcional salto para a frente, o mesmo não acontece com a compreensão do mundo e com a incompreensão entre os homens (2011, p. 21-22). 
Para fazer frente a esse estado de incompreensão entre os homens, é válido não esquecer que, na sala de aula, em qualquer âmbito ou nível, a leitura de poemas amplia a sensibilidade e o gosto pela linguagem literária e a capacidade de refletir sobre o mundo, as relações humanas e a própria questão da identidade. E, se "tempo e o espaço se inscrevem no poetar como matéria-prima de uma fábrica preexistente", o poema traz consigo expressivo potencial para ser força de resistência contra o lado obscuro das relações humanas (ou desumanas?) em nossos tempos. O texto lírico exige, contudo, abordagens críticas bem sustentadas teoricamente e sempre abertas a novos formatos de análise e recepção. Estudados isoladamente, em pares, comparados a outras linguagens, dialogando com outras nacionalidades ou aproximados pelas temáticas comuns, os poemas permitem, inclusive, que diversas trocas simbólicas (BOURDIEU, 1974) sejam reconhecidas, dimensionadas e discutidas.

O que vale para um planejamento geral vale, igualmente, para o ensino de poesia brasileira - componente curricular que não pode ser esquecido em estudos sobre a presença do poema nas salas de aula brasileiras -, visto que os pressupostos que norteiam a visão de Gens podem ser relacionados diretamente àquilo que propõem os Parâmetros Curriculares Nacionais (BRASIL, 1999) e a Lei de Diretrizes e Bases (BRASIL, 1996) que orientam as práticas de ensino. A atual configuração dos documentos legais sobre Educação baseia-se em critérios como transversalidade, interdisciplinaridade, sensibilidade, igualdade, identidade, entre outros. Tomando por parâmetro conceitos como esses, não é difícil perceber como a poesia (e a literatura em geral) pode ser instrumento precioso para que se alcancem objetivos de ensino baseados em tais valores. Afinal, o caráter multidisciplinar da própria literatura, a presença inquestionável da sensibilidade como canal para a fruição de um poema (ou de textos literários de outra natureza), e a capacidade que a literatura tem de promover reflexões sobre o ser, a sociedade, a justiça e temas de semelhante relevância são dados mais do que concretos para se lutar por um lugar mais digno para a literatura nas salas de aula.

A luta, entretanto, deve começar na universidade, uma vez que os principais articuladores de todo esse processo, envolvendo ensino e literatura nos níveis fundamental e médio, serão os profissionais formados pelos cursos de licenciatura em Letras. Sobre o tema afirma Gens: 
As Instituições continuam formando professores e, se o ensino da disciplina continua insatisfatório em grande parte das escolas, as Instituições responsáveis pela formação de professores não podem mostrar-se alheias a tal contexto, porque, nelas, o ensino de literatura continua preservando estruturas lineares e cronológicas, através de planos que fragmentam o ensino em unidades, estabelecem progressão do mais simples para o mais complexo, e descrevem, exaustivamente, objetivos a serem perseguidos (2009, p. 78).

Ampliando a colocação de Gens, vale lembrar que o ensino de literatura brasileira só se faz presente como conteúdo curricular no ensino médio, o que, em termos de reflexões sobre a presença do poema na sala de aula, exige um entendimento diferenciado em relação aos níveis fundamental e médio.

No âmbito do ensino médio, por exemplo, são importantes as considerações levantadas por William Cereja, em Ensino de literatura (2005), quando, também partindo de pesquisas de campo, o pesquisador pode observar de perto a realidade do trabalho com a literatura no ensino médio. Em uma de suas ponderações, Cereja assinala que o problema da abordagem historiográfica à literatura vem sendo um dos "nós" que amarram os currículos escolares a esquemas de memorização e fixação esquemática de nomes e obras. E a origem desse perfil historiográfico pode ser reconhecida nas próprias ementas de Literatura Brasileira que se recolhem de cursos de licenciatura em Letras de diversas universidades públicas e privadas brasileiras. Como exemplo, têm-se as ementas de "Literatura Brasileira 3 A", da Universidade Federal de Pernambuco (UFPE): "O Brasil dos anos de 1870 a 1900: contexto histórico, político e social; princípios filosóficos e científicos: estudo do realismo, naturalismo, parnasianismo e simbolismo"; a de "Literatura Brasileira II" da Universidade de São Paulo (USP):

\footnotetext{
4 Disponível em http://pt.scribd.com/doc/155462694/Perfil-Curricular-Letras-UFPE. Consulta realizada em 07 fev. 2014
} 
A disciplina tem como objetivo o estudo da literatura brasileira do segundo momento do século XX, com base no exame de obras, autores, gêneros e questões significativas da produção literária no período. Este estudo busca considerar tanto a consolidação e expansão do projeto modernista, bem como as especificidades de um novo contexto cultural que se desdobra em manifestações contemporâneas. (FLC0201) ${ }^{5}$

ou, ainda, a de "Literatura Brasileira III" da Universidade Tiradentes (UNIT):

Estudo das literaturas de expressão em língua portuguesa através de núcleos temáticos que possibilitem o diálogo entre as diversas manifestações literárias: nacionalismos, regionalismos, cosmopolitismo, globalização e lusofonia. Literatura moderna e Pós-modernismo (H112939). ${ }^{6}$

que privilegia o que chama de "núcleos temáticos", embora situando o recorte temático em manifestações literárias reconhecidas como "literatura moderna" e "literatura pós-moderna".

Em alguns casos, pode-se ainda constatar um investimento na reestruturação curricular a partir de um novo ponto de vista, tal como se observa nos currículos da Pontifícia Universidade Católica do Rio de Janeiro ${ }^{7}$, que no currículo anterior a 2012, apresentava a disciplina "Literatura Brasileira II" (LET1426), com a seguinte ementa:

A literatura da passagem do século XIX ao XX. As poéticas parnasiana e simbolista. O período pré-moderno.

5 Disponível em: https://uspdigital.usp.br/jupiterweb/obterDisciplina?sgldis=FLC0201\&co dcur $=8051 \&$ codhab $=204$. Consulta realizada em 07 fev. 2014

6 Disponível em http://www.unit.br/arquivos/graduacao/Letras_Portugues_Ementas.pdf. Consulta realizada em 07 fev. 2014

7 Informações disponíveis em: http://www.puc-rio.br/ensinopesq/ccg/letras_port-lit. html\#periodo_licen2012. Consulta realizada em 07 fev. 2014 
As manifestações da belle époque. Transição e sincretismo. A semana de arte moderna e a fase heróica do modernismo. A construção da identidade nacional. Cânones e margens em foco. O regionalismo de 1930. A renovação da literatura do pós-guerra: poesia, prosa e teatro. As vanguardas da década de 50 .

enquanto o currículo novo, que vigorou a partir de 2012, alterou os títulos das disciplinas, substituindo a nomenclatura de caráter sequencial (Literatura Brasileira I, II e III) por outras, que denotam discussões vinculadas à relação entre literatura e sociedade, tais como "Literatura e Nacionalidade", "Literatura e Modernidade" ou "Literatura e Contemporaneidade". E ementa de "Literatura e Contemporaneidade" (LET 1856), por exemplo, indica que a abordagem às obras será norteada por um eixo temático, a modernidade, e não por um eixo historiográfico:

Análise do conceito de modernidade literária. Tradição e ruptura na produção literária brasileira. Discussão do processo de formação das vanguardas históricas a partir das noções de transformação e permanência. Problematização dos conceitos de movimento, regionalismos e universalismos.

Essa reestruturação tem sido a tônica dos cursos de licenciatura em Letras engajados em questões trazidas pelas pesquisas que medem o desempenho dos estudantes brasileiros no que se refere à competência como leitores. De todo modo, convém lembrar que o PCN+ destaca a necessidade de estudantes de nível médio conhecerem a periodização da produção literária brasileira:

Os produtos culturais das diversas áreas (literatura, artes plásticas, música, dança, etc.) mantêm intensa relação com seu tempo. O aluno deve saber, portanto, identificar obras com determinados períodos, percebendo-as como típicas de seu tempo ou antecipatórias 
de novas tendências. Para isso, é preciso exercitar o reconhecimento de elementos que identificam e singularizam tais obras, vários deles relacionados a conceitos já destacados anteriormente (2002, p.65).

Sendo assim, cria-se um conflito entre propostas curriculares (em nível superior) mais condizentes com a formação eficaz de leitores de textos literários e as expectativas em relação aos conteúdos de literatura dos currículos de nível médio. E, nesse embate, não se pode eliminar o reconhecimento da importância da historiografia literária, pois, tal como afirma Cereja:

A nosso ver, a historiografia literária, em si, não constitui o problema central do ensino de literatura em nosso país. Ela pode trazer contribuições importantes para a compreensão de determinados textos, autores e épocas, da mesma forma que conhecimentos, de outras áreas, como história, filosofia, psicologia, sociologia, análise do discurso, etc. O problema é que, transformando-se no principal objeto e no principal objetivo do curso de literatura no ensino médio, ela vem centralizando, desde o último quartel do século XIX, a maior parte das atividades da disciplina, não dando espaço para outros tipos de abordagem da literatura, mais condizentes com a realidade e com os objetivos da educação oficial de hoje (2005, p.141).

Uma parceria concreta entre a universidade e a escola que redimensione o papel da historiografia literária no ensino médio e considere as novas demandas sociais do letramento literário certamente pode fazer dos poemas "palavras gritando contra o silêncio que aflige" e do espaço acadêmico uma verdadeira fonte "para instruir-se sobre o mundo", já que "tudo passa pela educação" (LIPOVETSKY; SERROY, 2011, p. 150).

As pesquisas realizadas com estudantes do campus Itabaiana do curso de Letras da Universidade Federal de Sergipe e em instituições de ensino 
fundamental e médio do estado de Sergipe partiram do reconhecimento da importância da contribuição da universidade para que as necessárias transformações nas rotinas escolares possam acontecer. A partir disso, as investigações mecionadas centraram-se na articulação de três aspectos relacionados à presença do poema, no âmbito inicial da literatura brasileira, no espaço educacional: a) as formas de inserção do poema nesses espaços; b) as dinâmicas que refletem a preocupação com o "letramento lírico", incluindo aí considerações sobre as bases teóricas que fundamentam essas dinâmicas e o próprio conceiro de "letramento lírico"; e c) as demandas e as propostas de transformações e reformulações que podem incidir para que a presença do poema, nas rotinas acadêmicas do ensino fundamental, médio e superior, seja recebida sem entraves, com qualidade na recepção (fruição) e mesmo com alegria (prazer). Esses três aspectos constituem diferentes enfoques à questão da dificuldade de se promover a visão do poema como texto "capaz de transformar o mundo", conforme descreveu Paz.

O primeiro aspecto refere-se, simultaneamente, à seleção de textos, aos suportes teóricos utilizados para abordar os poemas, à presença ou não de recortes hsitoriográficos e estéticos para essa abordagem, às formas de avaliação, ao uso de suportes didáticos como livros didáticos, antologias, apostilas e novas tecnologias, à abertura ou não das abordagens à produção contemporânea brasileira e às manifestações ligadas ao folclore, à música, a outras artes e áreas do conhecimento; e ao diálogo ou não entre a poesia brasileira e textos de outras nacionalidades.

O segundo trata das práticas de ensino de poesia que podem ser observadas no contexto das instituições de ensino fundamental e médio e nos próprios cursos de Letras, sem constituir, em momento algum, uma forma de policiamento ou interferência. O objetivo básico, quando se abordam essas práticas em pesquisas de campo, por exemplo, é chegar a dados que permitam reflexões próprias e trocas de visões entre docentes e discentes que, no espaço da universidade, devem exercer a função de repensar as práticas acadêmicas no que se refere ao trabalho com o poema em sala de aula. Os suportes eleitos para a análise desse item foram testes de sondagens especialmente preparados para serem aplicados em todas as turmas do curso de Letras da UFS/Itabaiana e outros, preparados para aplicação em escolas de ensino médio do estado de 
Sergipe. De igual modo, como aqui já se comentou, foi elaborado um teste de sondagem destinado a turmas do ensino fundamental.

A configuração dos testes foi determinada por leituras de textos teóricos e críticos sobre o gênero lírico, o ensino de leitura e a presença da lírica brasileira nos curriculos escolares e universitários; pelos documentos oficiais que regem o ensino de leitura e literatura nas instituições de ensino fundamental e médio; e pela consulta a dados estatísticos recentes sobre desempenho escolar e competência para a leitura no país.

Sobre "as demandas e as propostas de transformações e reformulações que possam incidir para que o letramento lírico, nos níveis básico e superior, seja incrementado", os projetos integraram as informações obtidas em pesquisa de campo às leituras teóricas e críticas realizadas, de forma a gerar produtos e atividades que contribuam para o ensino de poesia brasileira (e mesmo de poesia em geral). Nesse sentido uma ação foi executada: o projeto "Poetas modernos na escola I", desenvolvido no Colégio Estadual Vinte e Oito de Janeiro, no município Monte Alegre, no interior de Sergipe, no dia 23 de agosto de 2013, ao que se fará referência mais adiante.

De forma geral, no que se refere ao posicionamento das investigações em relação ao texto literário, cabe dizer que a filosofia que a norteia está afinada com o que afirma Umberto Eco:

As obras literárias nos convidam à liberdade da interpretação, pois propõem um discurso com muitos planos de leitura e nos colocam diante das ambiguidades e da linguagem da vida. Mas para poder seguir neste jogo, no qual cada geração lê as obras literárias de modo diverso, é preciso ser movido por um profundo respeito para com aquela que eu, alhures, chamei de intenção do texto (2003, p. 12).

Ou seja, ainda que aberta a diálogo com diversas posturas teóricas e pautada nos resultados e na análise dos dados recolhidos durante a pesquisa de campo, as propostas desenvolvidas tiveram como foco principal o texto em si, ao qual se relacionarão, em obediência aos rumos filosóficos do ensino 
de literatura, contexto e recepção, dando destaque à interdisciplinaridade, à formação do leitor e à constatação de que fenômenos como recepção e circulação de textos literários não podem prescindir hoje do diálogo com outras produções culturais e com manifestações de outras nacionalidades.

De outro lado, o foco na formação dos professores de língua e literatura brasileira orientou-se pela visão de Marisa Lajolo: "Um professor precisa gostar de ler, precisa ler muito, precisa envolver-se com que lê" (2006, p. 108) e pela de Antônio Cândido quando reflete acerca das injunções ou sobredeterminações que as diferentes possibilidades de acesso ao texto literário geram:

Em nossa sociedade há fruição segundo as classes na medida em que um homem do povo está praticamente privado da possibilidade de conhecer e aproveitar a leitura de Machado de Assis ou Mário de Andrade. Para ele, ficam a literatura de massa, o folclore, a sabedoria espontânea, a canção popular, o provérbio. Estas modalidades são importantes e nobres, mas é grave considerá-las como suficientes para a grande maioria que, devido à pobreza e à ignorância, é impedida de chegar às obras eruditas (1995, p. 256-257).

Além do artefato teórico estrito ou direcionado ao poema como texto, foram consideradas as tendências envolvidas nas práticas de leitura, no letramento lírico e na democratização do conhecimento apontados por Lipovetsky e Serroy quando se debruçam sobre a escola na sociedade contemporânea:

É preciso reafirmar: nossa escola não vai bem. Ela pede uma sacudida, sem dúvida uma reforma intelectual profunda que a reoriente e a deixe em condições de honrar suas promessas de formação e de mobilidade social. Precisamos denunciar os desvios de certo pedagogismo e reforçar as travas de segurança capazes de 
acabar com a imensa desorientação e desorganização (educativa e psicológica) fundamentadas na sociedade do hiperconsumismo. Isso não significa eliminar de uma prenda a cultura global na qual a escola existe. A escola certamente deve elevar o aluno, pô-lo acima do que ele vive e conhece no cotidiano, mas não vai conseguir isso sem levar em consideração o estado cultural do presente (2011, p. 153).

Também nesse viés, cabe a colocação de Rildo Cosson acerca da relação entre o letramento literário e o papel da escola:

[...] devemos compreender que o letramento literário é uma prática social e, como tal, responsabilidade da escola. A questão a ser enfrentada não é se a escola deve ou não escolarizar a literatura, como bem nos alerta Magda Soares, mas sim como fazer essa escolarização sem descaracterizá-la, sem transformá-la em um simulacro de si mesma que mais nega do que confirma seu poder de humanização (2009, p. 23).

Sustentados por essas referências, os dois projetos tiveram, como etapa de realização, a elaboração de testes de sondagem, a serem aplicados, respectivamente, no curso de Letras do campus Itabaiana da UFS e em instituições de ensino médio do estado de Sergipe. A existência de uma pesquisa em nível de Mestrado Profissionalizante em Letras (PROFLETRAS) por mim orientada que aborda a presença de poema em salas de aula do ensino fundamental completa a tríade dos níveis de investigação. Dada a necessidade de este artigo ater-se a limitações espaciais, registro, em seguida, como se deu a elaboração do teste de sondagem destinado a graduandos em Letras e quais foram os resultados obtidos. 


\section{O POEMA NA SALA DE AULA: SONDAGEM NA UNIVERSIDADE}

A sondagem entre os graduandos do curso de licenciatura em Letras do campus Itabaiana da UFS, realizada com 171 estudantes no segundo semestre de 2012, foi introduzida pelo seguinte esclarecimento:

Este teste de sondagem, vinculado ao projeto de pesquisa "No meio do caminho tinha um poema: repensando as teorias e as práticas em torno dessa presença", ao PIBIC e ao PIBIX, busca dar um suporte de informações que contribua para que se alcancem os diversos objetivos da pesquisa que podem ser sintetizados em: por meio de levantamento sólido de dados sobre as práticas relacionadas ao trabalho com o poema em sala de aula (em nível de graduação e de ensino médio), repensar essas mesmas práticas e propor atividades que contribuam para aprimorar e estimular o processo de letramento lírico e o gosto pelo poema, além de incrementar a formação do profissional de Letras no que tange às suas atividades futuras como docente. ${ }^{8}$

Ademais, sobre a estrutura do teste informou-se, entre outros, que:

\section{[...]}

4. O teste divide-se em duas etapas.

5. A etapa 1 (A e B) refere-se aos conteúdos de natureza teórica usualmente relacionados ao gênero lírico e consiste em um conjunto de questões às quais se relacionam opções que medem o grau de facilidade e/ou dificuldade para se realizar cada atividade listada (A) e em questões de reconhecimento de formas líricas (B). 6. A etapa 2 (A, B, C, D, E e F) refere-se à sua bagagem de conhecimentos sobre a produção lírica no contexto

\footnotetext{
8 Todos os trechos citados foram diretamente extraídos dos testes desenvolvidos e aplicados.
} 
específico da Literatura Brasileira (considerando época, estilo, autores/as, livros, poemas isolados) e às suas expectativas em relação à leitura e à interpretação de poemas.

7. No final do teste, haverá espaço para algum comentário ou sugestão desejada.

8. Agradecemos sua colaboração e pedimos que dedique especial atenção às diferentes opções de resposta da etapa 1, que requer uma reflexão especial sobre sua relação individual com a leitura e a interpretação de poemas.

A receptividade dos graduandos ao teste foi, em geral, bastante positiva. Representando 73\% dos estudantes matriculados, o total de testes realizados pode ser analisado como expressivo e legítimo, em termos de permitir conclusões sobre o perfil do curso em questão.

Antes das questões concernentes à "Etapa 1", apresentou-se um pequeno questionário, por meio do qual se obtiveram dados sobre: período em curso; faixa etária; sexo (com o único objetivo de confirmar a tendência culturalmente transmitida de as mulheres terem mais simpatia pela poesia); hábitos de leitura individual e familiar; acesso a acervo literário; e influências positivas e/ou negativas relacionadas ao contato com o poema no ensino médio. Privilegiaram-se, enfim, informações que permitissem definir um perfil de cada graduando interrogado e, de modo geral, um perfil do curso.

Do total dos testes de sondagem, a grande maioria dos graduandos identificou-se na categoria de gênero "sexo feminino" $(68,4 \%)$. O percentual que indica os que não quiseram identificar o gênero (13,6\%) é relativamente expressivo, o que pode indicar desinteresse ou desconforto em relação à computação desse tipo de informação ou, ainda, desatenção. A faixa etária predominante foi a de 21 a 25 anos de idade (46,6\%). As faixas etárias superiores totalizam 32,9\%, o que revela que boa parte dos estudantes está acima da faixa etária de estudantes de graduação que ingressam na universidade logo após o término do ensino médio. Esse percentual tanto pode indicar o ingresso tardio no curso superior, quanto uma mudança de curso ou realização de segunda graduação. 
Do grupo identificado como do sexo feminino, a resposta "de vez em quando" à questão "Você gosta de ler poemas?" representa 53,2\% do total, alcançando, pois, a maioria. O percentual das que declararam "não gostar de ler poemas" é bastante baixo (1,2\%). Do grupo identificado como "sexo masculino", os percentuais que representam o "gosto de ler" e o "de vez em quando" quase se igualaram (46,1\% e 46,4\%). Em termos gerais, o "gosto de ler poemas" alcançou margem de 39\%, enquanto o "gosto de ler de vez em quando" representou $52,4 \%$, o que indica um registro positivo da relação entre os discentes do curso de Letras e a leitura de poemas.

Quanto ao hábito de leitura, comparando os percentuais médios dos três grupos (sexo feminino, sexo masculino, e não identificado), destacou-se o percentual do sexo feminino que se definiu como "leitora assídua" (28,9\%), embora, também em termos gerais, seja o grupo "leitor ocasional" o mais representativo dos três grupos $(64,5 \%, 63,5 \%$ e $69 \%)$.

De outro lado, se no quadro anterior o percentual médio de estudantes que não gostam de ler poemas foi de $6 \%$, os 13,6\% de "não leitores" deste quadro podem indicar que metade desse percentual envolve estudantes que afirmaram gostar de ler poemas (sempre ou de vez em quando), mas, no entanto, não o fazem.

O baixo percentual de leitores assíduos do sexo masculino, matriculados no $1^{\circ}$ período, pareceu ratificar a ideia geral de que adolescentes e jovens do sexo masculino não costumam ser apreciadores de poesia. Os percentuais dos períodos seguintes já devem ser considerados a partir do fato de os estudantes estarem em contato direto com o gênero lírico na universidade.

Apesar de o percentual total de estudantes do curso que gostam de ler poemas ser de $39 \%$, apenas $12,8 \%$ dos estudantes indicaram terem lido poemas sempre (antes do curso), o que parece indicar simpatia recente pelo gênero. O baixo índice do hábito de leitura de poemas antes do curso de Letras também pode ser indicativo de uma realidade escolar: a maior ênfase no gênero narrativo e na leitura "obrigatória" de romances. Esse dado se confirma pelo baixo percentual de entrevistados que atribuiu à escola a função mediadora para a leitura de poemas (7\%).

A maioria dos estudantes (56,7\%) informou não ter em sua família o hábito da leitura e da escritura de poemas. De outro lado, é interessante ob- 
servar que o percentual de estudantes que escrevem poemas $(15,2 \%)$ é bem pequeno, se consideramos que cursos de Letras costumam reunir número expressivo de jovens com esse tipo de hábito. Esse indicador aponta para um perfil natural dos cursos de licenciatura em Letras do interior do país, que geralmente reúnem graduandos já orientados para a futura ação como professores de ensino fundamental e médio.

Quanto ao percentual referente à presença de livros de poesia no acervo pessoal dos estudantes, observa-se uma equiparação entre o "sim" $(47,8 \%)$ e o "não" (49\%). A equiparação entre os que têm ou não livros de poemas em sua biblioteca indica que a falta do hábito de leitura não pode ser plenamente justificada pela falta de acesso ao livro. Além disso, 100\% dos graduandos têm acesso à internet, meio em que circulam poemas de todas as épocas e autores.

As questões do item "a" da "Etapa 1" tinham como parâmetro indicar os graus de facilidade e dificuldade relacionados à leitura e à fruição de poemas e à capacidade do graduando em Letras de realizar determinados procedimentos de leitura. Essa aferição buscou confrontar os conhecimentos teóricos sobre o gênero lírico e a competência dos graduandos para colocarem em prática esses conhecimentos. Entre outras, os graduandos tiveram que assinalar o grau de facilidade (extrema ou relativa) ou dificuldade (alguma, muita, extrema) para realizar procedimentos como: reconhecer, no poema, a presença do eu-lírico (a instância lírica de enunciação); reconhecer quando um poema apresenta nível gráfico; reconhecer e nomear teoricamente a estrutura rímica de um poema (a rima e seus tipos); reconhecer as predominâncias lexicais em um poema; reconhecer, no poema, alterações lexicais como próteses, sufixações, aféreses, etc. (metaplasmos); compreender o sentido de um poema quando o mesmo possui um vocabulário mais antigo; reconhecer figuras de construção, tais como enumeração, digressão, polissíndeto, pleonasmo, etc.; reconhecer as figuras de linguagem presentes em um poema; perceber o diálogo entre um poema e o contexto a que se refere; reconhecer determinadas marcas estéticas de um poema no que se refere aos estilos de época; reconhecer, em um poema, marcas do estilo individual do/a poeta/isa; reconhecer os principais semas de um poema; relacionar conhecimentos de linguística a um poema; identificar marcas 
culturais ou regionais em um poema; produzir um texto analítico (estudo crítico) sobre um poema; comparar dois ou mais poemas, estabelecendo semelhanças e diferenças (conteúdo e forma); entre outras, em um total de 32 itens. Também foram oferecidas aos graduandos as opções "desconheço esse termo" e "depende do poema analisado".

O subitem " $b$ " centrou-se nas formas líricas e buscou verificar o domínio dos graduandos em relação à diversidade de formas que um poema pode assumir. Como o intento era o de fazer uma amostragem, selecionaram-se as formas "soneto", "ode”, "poesia épica", "haicai", "acróstico, "balada", "hino", "cordel”, "elegia”, poema encomiástico", "canção trovadoresca” e "lira" para verificar tanto o reconhecimento da forma em si, quanto de suas características.

Os percentuais obtidos, de forma geral, indicaram baixo índice de conhecimento das formas líricas. Embora algumas formas sejam conhecidas pela grande maioria dos estudantes, destaca-se, principalmente, o elevado percentual de desconhecimento de formas relevantes como a ode, o haicai (3,2\% indicaram conhecer a forma) e a elegia (13,2\% afirmaram conhecer uma elegia), por exemplo. Em relação à poesia épica, suas características foram reconhecidas por $58,4 \%$ (em média), mas o percentual de quem reconhece um poema como épico é um pouco mais baixo. Considerando que, no $3^{\circ}$ período, em "Literatura Portuguesa I", a obra Os Lusíadas faz parte do currículo, era de se esperar que os alunos desses grupos tivessem mais segurança quanto a essa forma. Em geral, há discrepância entre as respostas dos que afirmam conhecer as características de uma forma lírica e o percentual que indicou se podem reconhecer um poema como manifestação de uma forma específica, cujas características foram apontadas como conhecidas. Isso denota, como já se disse acima, insegurança em relação à aplicação da teoria na prática. O resultado, em geral, aponta para a carência de conhecimentos teóricos sobre as formas líricas.

A base teórica para a formulação dos itens da "Etapa 1" levou em conta os critérios de Salvatore D’Onofrio (2007) sobre os níveis gráfico, fônico, lexical, sintático e semântico de um poema para o estudo teórico do gênero lírico e algumas questões que já apontavam para a necessidade de se refletir sobre a futura atuação desses graduandos como professores e pesquisadores. 
A “Etapa 2" foi subdivida em seis seções, a saber:

a. O quadro abaixo apresenta uma série de estilos e/ou gerações líricas que se encontram nas histórias da Literatura Brasileira. No espaço em branco, solicita-se que você escreva de um a três nomes de poetas ou poetisas que reconhece estarem vinculados a esses momentos da poesia brasileira. Os nomes podem ser repetidos, caso você entenda que um mesmo poeta (ou uma mesma poetisa) possa ter transitado por momentos diferentes dessa trajetória.

b. O quadro abaixo apresenta uma série de temas usualmente presentes na produção lírica brasileira. No espaço em branco, solicita-se que você escreva de um a três nomes de poetas ou poetisas que se destacaram por privilegiar o tema em questão. Os nomes podem ser repetidos, caso você entenda que a produção de um mesmo poeta (ou uma mesma poetisa) possa ter se destacado com relevância em mais de uma temática.

c. O quadro abaixo apresenta as regiões brasileiras. No espaço em branco, solicita-se que você escreva nomes de poetas ou poetisas que tenham nascido na região. Caso se recorde do estado em que cada um/a (ou alguns/mas deles/as) nasceu, coloque a sigla do estado entre parênteses ao lado do nome.

d. O quadro abaixo apresenta uma série de poemas ou trechos de poemas. No espaço em branco, solicita-se que você, caso saiba, escreva o nome do poeta ou da poetisa que o escreveu.

e. O quadro abaixo apresenta uma série de títulos de livros de poemas (líricos e épicos) da Literatura Brasileira. No espaço em branco, solicita-se que você, caso saiba, escreva o nome do autor ou autora da obra. Observação: os nomes podem ser repetidos.

f. Como você descreveria as expectativas (positivas e/ou negativas) que sente em relação à leitura e à interpretação de um poema? A "obrigatoriedade" da leitura compromete positiva ou negativamente sua disposição para essas atividades (ler e interpretar)?

A organização desta etapa partiu do pressuposto que, se as ementas de Literatura Brasileira da Universidade Federal de Sergipe direcionam as dis- 
ciplinas para a abordagem historiográfica, como se vê na ementa de Literatura Brasileira III9:

\begin{abstract}
Aprofundamento do Modernismo de 22 e seu desdobramento. Estudo das características das obras literárias das gerações de 22/30/45. Estudo do romance de 30. João Cabral de Mello Neto, Clarice Lispector e Guimarães Rosa. Núcleos Temáticos: Identidade X alteridade $\mathrm{X}$ injustiça social $\mathrm{X}$ diferença de classes. A mimese social do romance. (Código 506061)
\end{abstract}

deveria se esperar dos graduandos um conhecimento adequado às propostas.

De outro lado, o estabelecimento de relações entre temas, autores e obras teve como propósito verificar a existência ou não da formação de um repertório básico de conhecimentos sobre a cultura literária brasileira, com destaque para o reconhecimento de poemas regularmente tomados como exemplos no percurso da lírica brasileira e usualmente citados em livros didáticos do ensino médio. A regionalidade dos autores completou a verificação, uma vez que volta e meia surge o debate sobre a presença ou não, nos currículos de cursos de Letras de diferentes estados do Brasil, de literaturas específicas, como a "Literatura Sergipana", que, no caso da UFS, está no currículo como específica e obrigatória.

A última seção buscou atender ao reconhecimento das expectativas dos graduandos em relação à leitura de poemas, oferecendo-lhes espaço para, em forma de texto discursivo, expressarem seu conforto ou desconforto em relação a esse aspecto.

O teste apresentou, ainda, no item "comentários" um "espaço livre para registro de impressões e sugestões que você deseje fazer".

$\mathrm{Na}$ "Etapa 2", alguns resultados foram surpreendentes.

O quadro "A" comprovou que a tradicional perspectiva historiográfica que apresenta a literatura brasileira como uma sucessão de estilos aos quais se vinculam os autores e suas obras não resulta em aquisição consolidada

9 Conforme se encontra no atual programa da disciplina . 
de conhecimentos. Com exceção de Gregório de Matos, cuja associação à literatura barroca foi razoavelmente expressiva, as margens percentuais de respostas corretas foram bastante inexpressivas. Exemplos disso são Gonçalves Dias, que foi citado em todos os períodos, mas com baixos percentuais de respostas $\left(1^{\circ}-6 \%, 3^{\circ}-21 \%, 5^{\circ}-34 \%, 7^{\circ}-22 \%\right.$ e $9^{\circ}$ - 29\%); e Cecília Meireles, cujo percentual mais alto de respostas aconteceu no $5^{\circ}$ período, com $10 \%$. A poesia realista, a decadentista e o poema processo não receberam qualquer resposta, o que possivelmente se relaciona à ausência de discussões sobre manifestações líricas mais específicas e menos comentadas nas historiografias literárias.

Em relação ao quadro "B", notaram-se poucos registros corretos. O tema "poesia”, por exemplo, indica, obviamente, poemas metalinguísticos. Os percentuais de respostas foram baixíssimos, principalmente se considerarmos a relevância da metalinguagem no modernismo e no pós-modernismo. Apesar de haver mais acertos que erros, o número de nomes incorretos (ou pela temática ou pelo fato de esses nomes não serem de "poetas brasileiros") foi expressivo, indicando pouca ou nenhuma consciência de importância dos poemas metalinguísticos. O tema "regionalismo", por sua vez, apresentou alto índice de incorreções, com a citação de muitos ficcionistas. O poeta mais citado foi João Cabral, mas com percentuais quase inexpressivos: $4 \%$ no $1^{\circ}$ período; $8 \%$ no 3 ; $; 2 \%$; no 5\%; $25 \%$ no $7^{\circ}$ : e $29 \%$ no $9^{\circ}$. A "crítica sociopolítica" poderia ter reunido muitos nomes do modernismo e do pós-modernismo, por exemplo. Contudo, os registros foram baixos. $\mathrm{O} 1^{\circ}$ período, obviamente influenciado pelo vestibular, teve em Drummond com um índice relativamente alto, $21 \%$, principalmente se comparado aos outros registros. O tema "cultura indígena" geraria, naturalmente, uma expectativa de maiores índices percentuais de acerto, já que é uma temática bem demarcada no romantismo, ainda que também o modernismo contemple bastante esse tema. Contudo os índices não foram tão altos: Gonçalves Dias, por exemplo, foi citado apenas por $2 \%$ do $1^{\circ}$ período; 85 do $3^{\circ} ; 15 \%$ do $5^{\circ} ; 25 \%$ do $7^{\circ}$ e $18 \%$ do $9^{\circ}$. O nome de Gonçalves de Magalhães também foi lembrado, mas houve muitas citações equivocadas, incluindo ficcionistas.

No que se refere à temática relacionada à "cultura afro-brasileira", Castro Alves é o poeta mais citado, e aparece em todos os períodos, o que indica 
um conhecimento bem tradicional do que seria a representação da cultura afro-brasileira em nossa poesia. Com exceção de Solano Trindade (PE) e Conceição Evaristo (MG), nomes de poetas como Lino Guedes (SP), Abelardo Rodrigues (SP), Eduardo de Oliveira (SP), Oliveira Silveira (RS), Adão Ventura (MG), Oswaldo Camargo (SP), Estevão Maya Maya (MA), Vilmar Alves Ribeiro (MA) e José Carlos Limeira (BA) não aparecem. Nas respostas também apareceram romancistas e autores de outras nacionalidades, como o angolano Ondjaki, além do rapper MV Bill.

Um dado, em especial, chamou a atenção: o número de vezes em que José de Alencar é citado, englobando diversos temas. Esse fato indica a não fixação do gênero literário como um fator para o registro da importância da obra de Alencar para a literatura nacional. Além disso, a não associação entre temas e poetas pode sugerir que a abordagem historiográfica, talvez por seu caráter sintético e panorâmico, não permita o registro sólido de discussões sobre temáticas abordadas pela poesia brasileira.

Os resultados do quadro "C" revelaram amplo desconhecimento dos estudantes acerca da produção lírica brasileira quando o recorte é regional. Reaparecem nomes de ficcionistas e há, mesmo dentro da pequeníssima margem de respostas, equívocos quanto à naturalidade de alguns poetas, inclusive de nomes conhecidos, como Drummond, cuja relação com Minas Gerais é uma de suas temáticas mais estudadas. Ainda assim, Drummond foi um dos nomes cuja naturalidade foi mais acertadamente citada. Houve poucos poetas sergipanos citados, assim como poetas que integram o viés afro-brasileiro de nossa lírica. Os resultados também demonstraram o privilégio que o cânone brasileiro dá às regiões sudeste e nordeste. Esse quadro indicou, portanto, a necessidade de um trabalho mais contundente no sentido de discutir as manifestações líricas regionais, uma vez que apenas o regionalismo nordestino na ficção parece ser registrado pelos estudantes do curso, daí a citação de diversos ficcionistas nordestinos.

O quadro " $D$ ", que pedia o reconhecimento de autoria, Os poemas obtiveram os seguintes percentuais médios de acerto: Vinícius (37\%), Adélia Prado (0\%), Olavo Bilac (5,4\%), Drummond (2,6\%), Oswald de Andrade (4\%), João Cabral de Melo Neto (10,8\%), Manuel Bandeira (1\%), Gregório de Matos (3,5), Cruz e Souza (5,7\%), Oswald de Andrade (9,6\%), Augusto 
de Campos (1,8\%), Raul Bopp (0\%), Cláudio Manuel da costa (0\%), Castro Alves (2,6\%), Mário de Andrade (4,2\%) e Cecília Meireles (10\%). Tais percentuais, com exceção do que se refere ao poema de Vinícius de Moraes, indicam baixíssima fixação de um conteúdo específico da poesia, o que é o caso do registro de poemas consagrados da literatura brasileira. Essa baixa fixação pode ter como razões: a falta de leitura de poemas; a falta de informação sobre poetas e poetisas brasileiros/as; o estudo de poemas sem o devido registro da autoria; e o esquecimento. Deve-se levar em conta que Vinícius de Moraes foi um poeta/compositor e cantor, o que faz com que sua autoria fique mais demarcada pela circulação nas mídias.

O quadro "E", que visava à medição do reconhecimento de autores de destacadas obras líricas da literatura brasileira, Os resultados médios obtidos foram os seguintes: Eu, Augusto dos Anjos, 15,4\%; Sentimento do mundo, Carlos Drummond de Andrade, 3,6\%; Lira dos vinte anos, Álvares de Azevedo, 16,2\%; Romanceiro da Inconfidência, Cecília Meireles, 8,2\%; Invenção de Orfeu, Jorge de Lima, 1,4\%; Poema sujo, Ferreira Gullar, 1,6\%; Os timbiras, Gonçalves Dias, 1,2\%; Martim Cererê, Cassiano Ricardo, 1,8\%; Estrela da vida inteira, Manuel Bandeira, 5,8\%; Marília de Dirceu, Tomás Antônio Gonzaga, 26,8\%; Espumas flutuantes, Castro Alves, 8,8\%; O cão sem plumas, João Cabral de Melo Neto, 12,8\%; Losango cáqui, Mário de Andrade, 0,4\%; Broquéis, Cruz e Souza, 3,8\%; Caramuru, Santa Rita Durão, 2\%; A rosa do povo, Drummond, 6,8\%; Viagem, Cecília Meireles, 0,6\%; Viva vaia, Augusto de Campos, 0,6\%; A luta corporal, Ferreira Gullar, 0\%; Obra poética, Cláudio Manuel da Costa, 0,4\%; Americanas, Machado de Assis, 0\%; Cante lá que eu canto cá, Patativa do Assaré, 0\%; Pauliceia Desvairada, Mário de Andrade, 10,8\%; Poemas dos becos de Goiás e estórias mais, Cora Coralina, 0\%; Pau-Brasil, Oswald de Andrade, 12\%; Tarde, Olavo Bilac, 0\%; Cobra Norato, Raul Bopp, 2,6\%; Dias e noites, Tobias Barreto, 5,4\%.

$\mathrm{O}$ índice de ausência de respostas foi altíssimo, o que revela pouco conhecimento dos títulos das obras mais importantes de poetas brasileiros. Também se destaca o índice de erros. O baixo índice de acertos em relação à obra de Tobias Barreto é relevante, considerando ser Barreto um poeta sergipano. Prosadores como Clarice Lispector, Alencar, Viana e Padre Antônio Vieira foram citados; assim como Camões. Um dos aspectos que deve ser 
ressaltado a partir da observação dessa tabela é a pouca ênfase individual que, nas aulas de literatura brasileira, se dá ao livro de poemas como um marco no percurso lírico brasileiro.

Quanto aos comentários do quadro "F”, em linhas gerais, foi possível perceber que a obrigatoriedade de leitura de determinados poemas ou obras líricas é vista como um fator positivo para o aprendizado no contexto acadêmico. Porém, a ausência de interesse pela leitura, a falta de tempo, a dificuldade de interpretar o texto literário e de compreender a sua linguagem, além de fatores como a má formação do docente do ensino médio e, por vezes, a precariedade do ensino da rede pública - ou da particular - acabam prejudicando a obtenção de resultados satisfatórios no que diz respeito aos conhecimentos literários. Além disso, e por outro lado, também se ressaltou a negatividade com que alguns discentes veem a questão da obrigatoriedade. Para eles, a imposição implica o não entendimento do que está sendo lido, bem como causa o desinteresse por parte do aluno, já que ele não se sente disposto a fazê-lo.

Algumas respostas, contudo, revelaram a maturidade dos graduandos no sentido de atribuírem a si próprios a origem das dificuldades em realizar um teste satisfatório para seus próprios padrões de exigência. Vejamos alguns comentários ilustrativos dessa postura em relação à expectativa quanto à leitura e à interpretação de poemas e à obrigatoriedade de realização de determinadas leituras:

\section{Comentários feitos pelos alunos do $1^{\circ}$ período:}

1. Expectativas positivas, pois a leitura desses poemas nos mostram os valores e as culturas passadas. Quanto à obrigatoriedade compromete positivamente a disposição para ler, mas o tempo é curto, o que é muito ruim. 2. Devido a um ensino médio meio aéreo sei que terei certa dificuldade para compreender e interpretar textos. Porém estou disposta a ler mais e aprimorar meus conhecimentos.

3. Negativa, pois eu vi que preciso ler mais. Quanto à obrigatoriedade, compromete positivamente porque 
começa de forma obrigatória, mas podemos aprender a gostar cada vez mais.

4. Realmente é lamentável a falta de prática na leitura, por esse motivo é que talvez nos deparemos com dificuldade de compreensão, a "obrigatoriedade" talvez sirva de estímulo e influencie de forma positiva na vida das pessoas.

5. Embora não tenha o hábito de ler poemas, é de extrema importância a sua leitura, não só ler, mas tentar interpretar. Quanto à obrigatoriedade, ela é positiva para termos mais aprendizado sobre poemas e seus poetas.

6. As expectativas são positivas, mas eu tenho uma péssima memória para distinguir o poeta e o seu tempo, consigo mais identificar para com sua obra do que o universo e principalmente nesse momento não me lembro de nenhum, deu um branco.

\section{Comentários feitos pelos alunos do $3^{\circ}$ período:}

1. As expectativas são negativas em relação a leitura e a interpretação de um poema pelo fato de ter tido uma base teórica de literatura precária, pois os professores que tive não me incentivaram a ler obras e nunca trabalharam nenhuma em sala de aula.

2. Quando leio um poema minha mente se abre para novas ideias, embora muitas vezes tenho dificuldade na interpretação. Quanto à obrigatoriedade da leitura faz com que o aluno se empenhe e aprenda mais.

4. Precisamos ser incentivados a ler com menos pressão e mais prazer. Algo deve ser feito para que a leitura seja uma rotina gostosa.

5. Negativas. A obrigatoriedade compromete positivamente, mas infelizmente minha disposição foi pouca e só aprendi o necessário exigido pelo professor. $\mathrm{Na}$ 
verdade só tinha interesse em ler livros de autoajuda. 6. As dificuldades ao tentar interpretar um poema são enormes, isso devido ao fato de não ter tempo disponível para ler. Uma pessoa que não é habituada a ler não tem como se sair bem na interpretação de um poema.

\section{Comentários do $5^{\circ}$ período:}

1. Negativas, pois eu tenho certa dificuldade em interpretar poemas devido ao não hábito de ler. Com certeza positivamente, pois através da litura o texto ficará mais fácil de interpretar.

2. Talvez ler e interpretar poemas sejam o mais atraente no curso de letras. Portanto, acredito que isso seja um aspecto positivo. Muitas vezes a obrigatoriedade dessas leituras é um aspecto negativo. Gosto de ler por prazer e não por obrigação, apesar de ser necessário.

3. A obrigatoriedade não deve ser considerada por um ângulo negativo, pois você acaba pegando o gosto pela leitura e dessa forma você conhece mais poesias e poetas.

4. Minhas expectativas são negativas apesar de muitos professores passarem para o aluno todo esse conteúdo, como também tem alguns professores que sequer falam em escritores e obras, o que compromete parcialmente o nosso futuro para trabalharmos com os alunos e também a nossa leitura.

5. Desde o ensino médio existe precariedade em relação ao ensino e ao incentivo a leitura de poesia. $\mathrm{Ou}-$ tro aspecto negativo é a preferência dos docentes pela prosa, uma vez que para alguns o ensino de poesia está em desuso.

6. São expectativas positivas tendo em vista que esse tipo de texto nos direciona para o conhecimento das profundezas da alma humana e alcança o principal 
âmago das coisas, o de revelar verdades. Positivamente, pois necessito dela constantemente para me aperfeiçoar como sujeito e ter consciência do lugar que ocupo no mundo como sujeito histórico-social.

7. Negativa, pois comecei a analisar poemas a partir do curso de letras, no ensino fundamental e médio não tive cobranças nem noção do que é um "poema", com relação a sua estrutura, tema, rima, cadeia literária, autor, características, etc. Mas venho melhorando e aperfeiçoando cada vez mais o estudo pelos poemas.

\section{Comentários do $7^{\circ}$ período:}

1. Não gosto de estudar poemas, pois não consigo interpretar suas várias etapas e me sinto frustrada em relação a esse tipo de atividade.

2. A leitura de um poema é algo bastante agradável, o eu não torna muito bom são os tipos de análises impostas aos alunos.

3. A leitura, principalmente a análise desses poemas não foram incentivados na escola. Na realidade os poemas são levados em consideração apenas quando precisa trabalhar a gramática. Na disciplina de literatura há apenas uma abordagem biográfica do poeta, com rápidas citações dos poemas.

4. Em minha opinião, afirmo uma extrema carência literária acerca de poesia, muitas vezes lemos poesia porque gostamos do tema/autor, ou simplesmente porque somos cobrados. No entanto, nos dois casos questões mais complexas não são abordadas e a leitura se limita à mera decodificação de sinais gráficos.

5. Minha expectativa deve ser positiva, mas sinto que minha leitura está em base de $30 \%$ em detrimento dos $90 \%$ que um educador formado em Letras deveria ter. Caso não fosse a insistência dos professores acadêmi- 
cos eu não leria muito. Reconheço os poemas, mas não identifico os autores.

\section{Comentários do $9^{\circ}$ período:}

1. As expectativas devem ser as melhores possíveis, pois geralmente um poema traz em seu bojo muitas informações referentes à época em que foi escrito atrelado à temática abordada. Geralmente quando o aluno é obrigado a realizar alguma tarefa ele não gosta muito, isso pode atrapalhar seu desempenho.

2. A leitura de obras poéticas deve ser feito por prazer, não por obrigação. Deve-se estimular os alunos a praticar a leitura de pequenos poemas, para que o gosto pela literatura seja estimulado e transformado em hábito cotidiano.

3. Poesia para mim é sempre um prazer. É mágica a maneira como os poetas escrevem a vida com palavras doces ou às vezes sobreas. É bem melhor escolher ler, a obrigatoriedade torna a leitura menos prazerosa. 4. Creio que o hábito de leitura de poemas, bem como leituras em geral, depende muito do interesse pessoal. Aquilo que lhe é forçado, geralmente, não deixa saldos positivos. Atualmente os jovens têm contato direto com "novas" leituras e o interesse por poesias tende ao declínio, no meu ponto de vista.

5. Ler e interpretar poemas é muito interessante, mas muitas vezes se torna difícil por nossa falta de preparo. Acredito que esse tipo de gênero deve sim fazer parte das atividades inicialmente de forma obrigatória para depois passar a ser um hobby.

6. A leitura e a interpretação de um poema remetem a vários contextos que precisam estar incorporados na leitura. É necessário que esta tenha um "horizonte de 
expectativa", um repertório bem "apurado" para conceber a leitura efetivamente.

Os comentários finais permitiram verificar uma aprovação geral à realização desse tipo de sondagem. Ainda que muitos tenham expressado a decepção com o próprio desempenho, essa decepção foi encarada como um estímulo para mudanças nos hábitos de leitura e comprometimento com a busca por bases teóricas que ampliem a competência de cada graduando como leitor. Seguem alguns comentários que ilustram a tonalidade geral do conteúdo recolhido nesse último item:

1. Nota-se grande dificuldade dos estudantes em relação ao conhecimento do assunto. Isso é fruto de uma educação em vários aspectos, familiar, escolar e da própria pessoa, pois ninguém aprende o que não quer aprender. Porém a leitura é algo importante para qualquer interpretação.

2. Não me saí bem nessa pesquisa, pois já estou há um bom tempo parado e não me recordo de algumas coisas. Sugestão: gostaria que tivesse uma revisão com alguns temas aqui abordados.

3. Essa pesquisa foi bacana, percebi que tenho muito a aprender sobre poemas e poetas e suas várias épocas e classes literárias, devo-me esforçar o máximo.

4. Adoro o curso de letras e quero poder me apaixonar mais por ele. A minha sugestão é que em todas as aulas tenha um poema novo para podermos debater e interpretar, pois durante os meus anos de estudo nunca tive um professor que gostasse de lê ou que me mostrasse certos conhecimentos sobre poemas.

5. Infelizmente esse questionário me deixou frustrada porque nunca me preocupei em fazer uma análise sobre os autores e suas obras. Com ele veio a necessidade de ir em busca de melhor aprimorar meus conheci- 
mentos e perceber o quanto é necessário adquirir conhecimento sobre essas obras.

6. Questionário ótimo! Ao responder percebi que não sei de quase nada sobre literatura.

7. Este projeto é válido para incentivar o hábito da leitura de vários poemas e aprofundar os conhecimentos adquiridos durante as aulas de literatura e familiarizar o contato com a reflexão de ler mais e a importância da leitura para a formação dos educados.

8. Senti com essa pesquisa que preciso aumentar meus conhecimentos em relação ao que foi apresentado no questionário. Na verdade todos nós temos que ter um conhecimento muito grande em relação a tudo isso, se quisermos ser profissionais competentes, pois o meio vai cobrar e quando isso acontecer pode ser tarde para se aprender. Devo agradecer pela pesquisa, pois a partir de agora passarei a ler mais sobre literatura.

9. Há um erro na grade de Letras com relação a literatura: Literatura Brasileira I já começou com o romantismo, os professores dessa área é que escolhem os autores com que se identificam mais, não queres saber se esses autores serão importante ou não para os alunos. 10. Realmente estou constrangida em responder este questionário, pois estou cursando o $5^{\circ}$ período de letras e não consigo diferenciar os autores, suas obras e suas respectivas escolas literárias.

11. Esse questionário me pegou de jeito, pois estou no $5^{\circ}$ período e não sei identificar e nem reconhecer nada do que foi perguntado em relação aos autores e aos poemas. Sugiro que seja promovido um curso de extensão para expor sobre os autores e os poemas, particularmente minhas dificuldades foram muitas e futuramente quando for lecionar quero saber responder aos meus alunos tudo sobre literatura. $\mathrm{O}$ curso de 
extensão só iria enriquecer nosso aprendizado para sairmos mais preparados.

12. Aprovo a iniciativas, através deste questionário será possível observar o caos que é a escola pública, pois os alunos chegam a universidade com um conhecimento mínimo de poesia.

13. Através desse teste percebi que não estou dando a devida importância ao meu curso, pois deixei a desejar, só agora percebi o quando eu poso ganhar em termos de cultura individual com o conhecimento adquirido na minha graduação. Com isso vou passar a valorizar todos os conteúdos e seguir com as leituras. Muito obrigada.

14. Identifico em mim que minha dedicação ao curso, ou a formação deveria estar mais centrada, mas só detectei a partir desse teste de sondagem. Obrigada! 15. Como é patente, há uma necessidade de olhar a poesia como uma fonte de conhecimentos que dentro do contexto acadêmico permite, assim como a prosa, uma maior amplitude para o pensamento e para os sentimentos. Ainda falta um olhar mais voltado para o texto lírico, sendo percebida uma carência de aulas de literatura brasileira mais focadas na poesia e também outras atividades como cursos de extensão que possibilitam um maior contato com as formas poéticas. 16. Nunca havia parado para refletir sobre a lacuna que existe na minha formação com relação à poesia. Confesso que lia mais poesias antes de entrar na UFS, apesar disso parecer contraditório, mas é verdade. Acho que algo que traz tanta satisfação e conhecimento poderia ganhar mais espaço no nosso curso.

17. Após responder a esse teste fica a impressão de que pouco me dediquei ao assunto poesia até agora. Neste momento da minha vida acadêmica vejo que não estou 
nem um pouco preparado para trabalhar o conteúdo de língua portuguesa na educação básica.

De forma geral, o teste de sondagem promoveu um movimento interessante no campus, trazendo o poema ao centro das reflexões sobre leitura, literatura, ensino, formação do professor de ensino básico, currículo do curso, entre outras.

Uma análise profunda e criteriosa de todos os dados recolhidos não pode prescindir do envolvimento de todos os docentes que trabalham com leitura, literatura e teoria literária. E certamente esse material dará um suporte interessante à reestruturação, em pleno desenvolvimento, do currículo do curso de Letras do campus Itabaiana da UFS.

\section{CONCLUSÃO}

Testes dessa natureza não podem ser tomados como parâmetro absoluto para se discutirem, em caráter global, questões relacionadas ao trabalho com o poema nas salas de aula. E, certamente, muitos dos resultados obtidos retratam situações específicas de Letras/UFS/Itabaiana, que pedem discussões igualmente específicas. Entretanto, pela abrangência de seus itens, acreditamos que a aplicação do teste em outras instituições de ensino possa ser útil no sentido de se estimularem a reflexão sobre a complexa presença do poema na sala de aula e as decorrentes considerações sobre a organização curricular de cada curso no que se refere a essa presença.

Por outro lado, cabe registrar que o impacto do teste de sondagem entre os graduandos do curso de Letras da UFS/Itabaiana levou 14 estudantes da disciplina "Literatura Brasileira III" a se envolverem no projeto "Poetas modernos na escola I", projeto piloto que consistiu na elaboração de apresentações em power-point sobre oito nomes da lírica modernista: Manuel Bandeira, Oswald de Andrade, Mário de Andrade, Cassiano Ricardo, Carlos Drummond de Andrade, Cecília Meireles, Murilo Mendes e Vinicius de Moraes, a serem divulgadas a estudantes do ensino fundamental e médio do Colégio Estadual Vinte e Oito de Janeiro, no município Monte Ale- 
gre, situado no interior de Sergipe. As apresentações buscaram reunir texto, contexto, autor e obras, além de traços do estilo individual de cada poeta, fazendo uso de ilustrações e propostas de atividades criativas a serem desenvolvidas após o trabalho com os materiais produzidos. Durante todo o dia 23 de agosto de 2013, esses graduandos, em espaços oferecidos pelo colégio, apresentaram seus trabalhos, interagindo com um público médio de 250 estudantes por turno, e fazendo uso de diversos recursos criativos, como vídeos por eles preparados, músicas, trabalhos artísticos, declamações, entre outros. A presença de autoridades locais e membros de outras instituições de ensino da região estimularam os graduandos envolvidos a refletirem sobre a real necessidade de investirem na melhor qualidade do ensino no estado.

O evento teve projeção tão positiva, que o professor de literatura do colégio, Carlos Alexandre do Nascimento, logo em seguida criou um projeto de multiplicação dos trabalhos apresentados e oferecidos ao colégio, através da participação dos próprios estudantes da instituição. $\mathrm{O}$ interesse dos alunos da escola em levar as apresentações a outras escolas do sertão sergipano resultou na inscrição de 100 participantes no projeto e criou, inclusive, a necessidade de o professor ampliar o número de poetas abordados. Também foi firmado o compromisso, por parte da UFS, de voltar ao colégio em 2014 com novas apresentações envolvendo outros nomes. Atualmente, novo grupo de graduandos prepara apresentações sobre Olavo Bilac, Raimundo correia, Augusto dos Anjos, Guilherme de Almeida, Augusto Frederico Schmidt e Ledo Ivo

Voltando à definição pessoal de poesia como "ampulheta acionada pela voz da urgência”, propõe-se aqui que também sejam urgentes as mudanças de postura por parte de docentes de literatura brasileira, teoria literária e leitura nas universidades, de modo a evitar que o traço de individualidade natural e positivo que as características de cada docente imprimem a cada curso de licenciatura em Letras não se sobreponha às reais necessidades de formação dos futuros professores. Que os cursos de licenciatura em Letras, além dessas marcas individuais, que destacam a própria trajetória de cada docente e seu envolvimento com temáticas específicas no campo da literatura e da língua, também tenha como princípio norteador o diálogo com a sociedade, com as questões específicas de cada contexto sociocultural e, 
também, com as expectativas dos discentes. De outro lado, que as sondagens relativas à realidade escolar nos níveis fundamental e médio sejam práticas recorrentes, a fim de que também os docentes envolvidos apenas com graduação e pós-graduação possam se manter atualizados em relação ao universo no qual atuarão os graduandos sob sua responsabilidade.

Concluo ratificando como principal objetivo das investigações e sondagens sobre o tema "o poema na sala de aula" o desejo de atuar positivamente como docente e pesquisadora na área de Ensino de Literatura e Literaturas de Língua Portuguesa no campus de Itabaiana da UFS, colaborando, principalmente, para que os alunos do curso de licenciatura em Letras, ao deixarem a universidade, estejam mais seguros e conscientes de seu potencial como professores, mediadores de leitura e divulgadores da produção literária nacional e do poema em especial como textos de fruição e de prazer.

\section{REFERÊNCIAS}

BOURDIEU, Pierre. A economia das trocas simbólicas. São Paulo: Perspectiva, 1974.

BRASIL. Lei 9.394/96, de 20 de dezembro de 1996. Estabelece as diretrizes e bases da educação nacional. Diário Oficial [da] República Federativa do Brasil. Brasília, DF, 23 de dez. de 1996.

BRASIL. PCN+Ensino Médio: orientações educacionais complementares aos Parâmetros Curriculares Nacionais. Vol. Linguagens, códigos e suas tecnologias. Secretaria de Educação Média e Tecnológica -Brasília: MEC; SEMTEC. 2002. 104 p.

BRASIL. Ministério da Educação. Secretaria de Educação Média e Tecnológica. Parâmetros curriculares nacionais: ensino médio. Brasília: MEC/SEMTEC, 1999. 
CANDIDO, Antonio. A literatura e a formação do homem. Ciência e cultura. São Paulo, v. 24, n. 9, p. 803-809, set. 1972.

CEREJA, William Roberto. Ensino de Literatura: uma proposta dialógica para o trabalho com literatura. São Paulo: Atual, 2005.

COSSON, Rildo. Letramento literário: teoria e prática. São Paulo: Contexto, 2009.

D’ONOFRIO, Salvatore. Forma e sentido do texto literário. São Paulo: Ática, 2007

ECO, Umberto. Sobre algumas funções da literatura. In: Sobre a literatura 2. ed. Rio de Janeiro: Record, 2003.

GENS, Armando. Formação de professores de literatura brasileira: conservação e desvio. In: GOMES, Carlos. (Org.). Língua e literatura: propostas de ensino. São Cristóvão: Editora UFS, 2009. p. 65-80.

LAJOLO, Marisa. Do mundo da leitura para a leitura do mundo. São Paulo: Ática, 2006.

LIPOVETSKY, Gilles; SERROY, Jean. A cultura-mundo: resposta a uma sociedade desorientada. Trad. Maria Lúcia Machado. São Paulo: Companhia das Letras, 2011.

PAZ, Octavio. O arco e a lira. Rio de Janeiro: Nova Fronteira, 1982.

RAMALHO, Christina. Território lírico. In: ___ PASCALE, J. G. (Org.). Água terra fogo ar. Crônicas elementais. Rio de Janeiro: UAPÊ, 2011. p. 72-74.

SANTOS, Leonor Werneck dos; DUARTE, Márcia Nunes. A literatura e o ensino de leitura. In: IX CONGRESSO NACIONAL DE LINGÜÍSTICA E 
FILOLOGIA, 9., 2005, Rio de Janeiro. Anais eletrônicos... Rio de Janeiro: 2005. Disponível em: http://www.filologia.org.br/ixcnlf/6/07.htm. Acesso em: 11 abr. 2012

Recebido em 02/03/14

Aceito em 25/04/14 